\title{
A sample formation procedure to obtain homogeneous post- erosion particle size distribution
}

\author{
Shijin $\mathrm{Li}^{1}$ and Adrian R. Russell ${ }^{1, *}$ \\ ${ }^{1}$ Centre for Infrastructure Engineering and Safety, School of Civil and Environmental Engineering, The University of New South \\ Wales, Sydney, NSW 2052, Australia
}

\begin{abstract}
Internal erosion (suffusion) is caused by water seeping through the matrix of coarse soil and progressively transporting out fine particles. The mechanical strength of soils within water retaining structures may be affected after internal erosion occurs. However, most experimental investigations on the mechanical consequences of internal erosion have used triaxial tests on samples having nonhomogeneous particle size distributions along their lengths. Such nonhomogeneities arise from the most commonly used sample formation procedure, in which seeping water enters one end of a sample and washes fine particles out the other. In this paper a new soil sample formation procedure is presented which results in homogeneous particle size distributions along the direction of seepage, that is at all locations along a sample's length.
\end{abstract}

\section{Introduction}

Internal erosion (suffusion) is caused by water seeping through the matrix of coarse soil and progressively and selectively transporting out fine particles. The transportation and migration of fine particles gradually changes the grading, increases the porosity, and affects the hydraulic and mechanical characteristics. It is a particular concern for cohesionless gap-graded soils in dam cores, filters and transition layers. Internal erosion of the soils forming water retaining structures may occur and lead to expensive maintenance costs or, in extreme cases, total collapse. Around $50 \%$ of dam failures and dysfunctions are caused by internal erosion [1].

An increasing number of triaixal erosion tests [2-6] have been conducted by researchers to investigate the mechanical influences of internal erosion. However, it has been well reported that the fine particles within the soil specimen having undergone internal erosion are not distributed uniformly. This phenomenon was observed by Kenney and Law [7] in tests on granular soils subjected to downward seepage tests. They found that granular soils having undergone internal erosion usually consist of a top transition zone, which is the coarsest section, a central homogeneous zone and a bottom transition zone, where the loss of fine particles is the least. The loss of fine particles results in coarsening the soil and downward shifting of the grain size distribution curve from its original position. Chang and Zhang [2] and $\mathrm{Ke}$ and Takahashi [4] also reported that the post-erosion grain size distribution curves for top, middle and bottom layers of the specimen moved downwards. More fine particles eroded out of the top layer than the bottom layer. This significant non-uniformity of distribution of fine particles within the eroded soils may cause significant non- uniformity of water content and strengths throughout the specimen. Ideally, prior to the subsequent mechanical test, a soil sample having undergone internal erosion should have a uniform grain size distribution throughout.

This paper, which is restricted to a gap-graded, cohesionless and compacted soil, will introduce a simple procedure of forming soil specimens which have uniform post-erosion grain size distributions.

\section{Testing apparatus}

A triaxial apparatus, modified to enable erosion, is used to study the initiation, rate of progression and mechanical consequences of internal erosion. The apparatus consists of a triaxial compression testing system, a drainage system enabling water to seep through samples and cause erosion, a constant head water tank to drive the seepage, and system to collect the water once it has seeped through the soil. The system is broadly similar to others $[2-4,6$, 8]. A schematic illustration is shown in Fig. 1.

The triaxial testing apparatus, used to test cylindrical samples $200 \mathrm{~mm}$ in diameter and $400 \mathrm{~mm}$ in height, is displacement-controlled. The base pedestal and top-cap contain funnel-shaped voids to enable seepage water containing soil particles to exit a sample through its ends and pass into a collection system. Perforated stainless steel discs cover each funnel-shaped void and provide and act as rigid base and top sample boundaries. The perforations are circular, $5 \mathrm{~mm}$ in diameter, and make a grid pattern with a center-to-center spacing of $8 \mathrm{~mm}$. The $5 \mathrm{~mm}$ perforation size is sufficiently large to prevent clogging by fine particles. They are sufficiently small to prevent coarse particles from passing thus preventing collapse of a sample. The largest eroded particle is less than (and usually much less than) $15 \%$ of the maximum

\footnotetext{
* Corresponding author: a.russell@unsw.edu.au
} 
particle size [9], being $2 \mathrm{~mm}$ in average in this study. All flow channels and fittings have an internal diameter of 7.5 mm.

Seepage water can be introduced and passed through samples in both upward and downward directions to cause particle removal under a range of confining stresses and hydraulic gradients prior to shearing. Passing water through two directions enables a more homogeneous sample to be achieved prior to triaxial testing than possible by $[2,5,10]$. In these studies, equipment permitted only the one directional passage of water causing significant variations in particle size distributions along the sample lengths. The seepage water is supplied via a constant head tank. The constant head tank comprises a watertight barrel fitted with an inlet ballcock valve, and continuous water supply can be achieved. In the tests conducted here the, water tank is located $1.24 \mathrm{~m}$ above the base of the sample, causing an average hydraulic gradient $\mathrm{i}=3.1$ to be imposed across the sample. Higher or lower hydraulic gradients can be achieved by raising or lowering the constant head tank.

Once internal erosion is initiated, and particles begin to wash out from the sample, the flow rate and the mass of eroded soil can be determined. The collected water is allowed to stand for a period of time so that suspended soil particles settle out from the water.

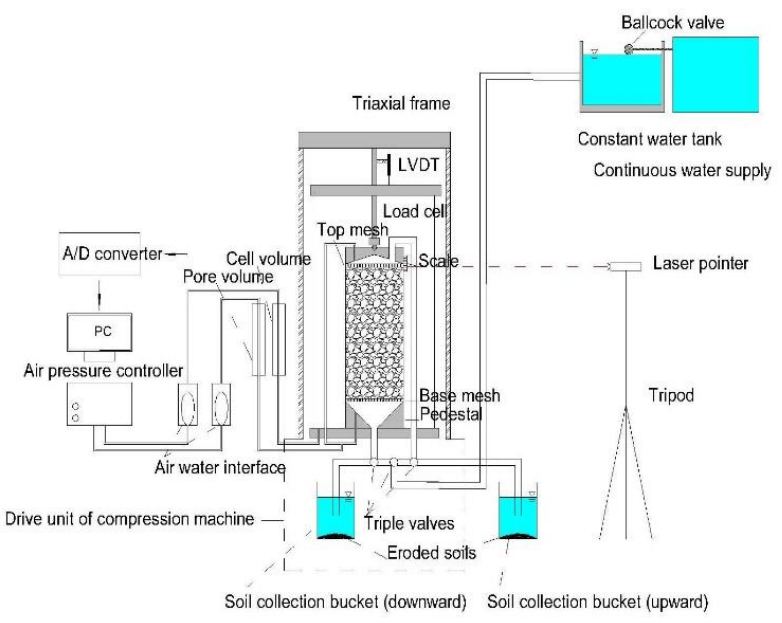

Fig. 1. Schematic diagram of the internal erosion triaxial testing system.

\section{Test soil preparation}

\subsection{Soil material}

The soil for this study is a mixture of three base materials comprising silt, sand and gravel-sized particles in different proportions. The three base materials are referred to as silica $60 \mathrm{G}, 5 \mathrm{~mm}$ basalt and $10 \mathrm{~mm}$ basalt. The particle size distribution of each soil is shown in Fig. 2. They are mixed in the proportions $0.26: 0.10: 0.64$ to produce a gap-graded soil for testing, having a gravel content of $58.2 \%$, with a full particle size distribution also shown in Fig. 2. This particular gap-graded soil is selected to ensure that erosion will occur, noting that soils having gravel contents of around $60 \%$ (or larger) are internally unstable [9]. The gravel particles act as the primary load bearing skeleton in the soil, enabling fine particles to be washed out from the spaces around the gravel. Other physical properties of the test soil are summarized in Table 1. The erodibility of the soil mixture is evaluated as internally unstable according to several particle size distribution-based criteria [7, 11-16] as shown in Table 2.

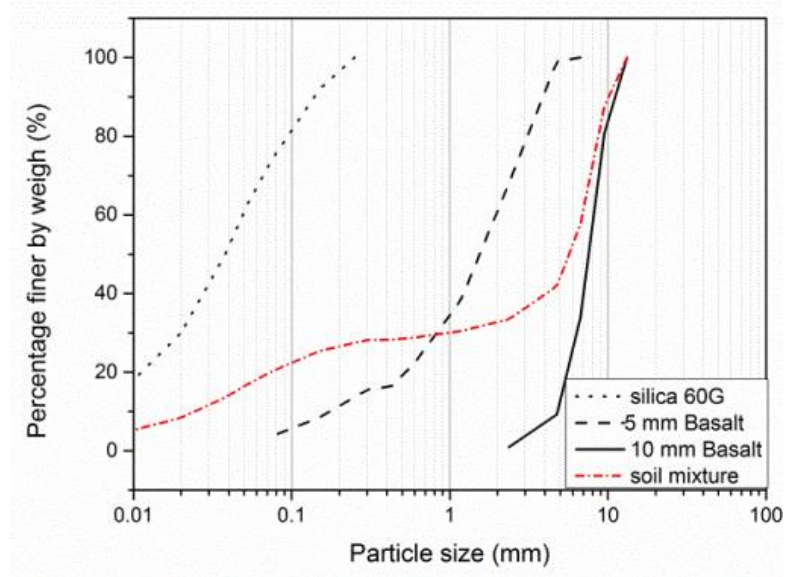

Fig. 2. Particle size distribution of soils.

Table 1. Physical properties of the gap-graded test soil.

\begin{tabular}{cc}
\hline Physical property & Value \\
\cline { 2 - 2 } $\mathrm{d} 90$ & 10.1 \\
$\mathrm{~d} 60$ & 6.9 \\
$\mathrm{~d} 30$ & 5.7 \\
$\mathrm{~d} 15$ & 0.97 \\
Mean particle size d50, mm & 0.04 \\
Effective particle size d10, mm & 0.02 \\
Uniformity coefficient $\mathrm{Cu}, \mathrm{mm}$ & 284.6 \\
Curvature coefficient Cc & 5.6 \\
h'=d90/d60 & 1.5 \\
$\mathrm{~h}=\mathrm{d} 90 / \mathrm{d} 15$ & 232 \\
Specific gravity, Gs & 2.73 \\
Minimum dry density, g/cm3 & 1.79 \\
Maximum dry density, g/cm3 & 2.49 \\
USCS (ASTM D2487-11) & $\mathrm{GM}$ \\
Particle description & sub- \\
& angular \\
\hline
\end{tabular}

$\mathrm{dx}$ denotes the particle size finer than which the soil mass by percentage is $\mathrm{x} \%$

Table 2. The evaluation of the mixture's erodibility.

\begin{tabular}{lll}
\hline Criteria & $\begin{array}{l}\text { The mixture is internally } \\
\text { stable if }\end{array}$ & $\begin{array}{l}\text { Stability of } \\
\text { gap-graded soil }\end{array}$ \\
\hline U.S. Army (1953) & $\mathrm{C}_{\mathrm{u}}<20$ & $\mathrm{U}$ \\
Istomina (1957) & $\mathrm{C}_{\mathrm{u}} \leq 20$ & $\mathrm{U}$ \\
Lubochkov (1965) & $(\Delta \mathrm{S} 1 / \Delta \mathrm{S} 2) / \mathrm{F} \leq 1$ & $\mathrm{U}$ \\
Kezdi (1979) & $\left(\mathrm{d}_{15 \mathrm{c}} / \mathrm{d}_{85 \mathrm{f}}\right)_{\max 4}$ & $\mathrm{U}$ \\
Kenney and Lau & $(\mathrm{H} / \mathrm{F})_{\min } \geq 1(0<\mathrm{F}<0.2)$ & $\mathrm{U}$ \\
$(1985,1986)$ & & \\
Burenkova & $0.76 \log \left(\mathrm{h}^{\prime \prime}\right)+1<\mathrm{h}_{0}<1.86$ & $\mathrm{U}$ \\
$\quad(1993)$ & $\log \left(\mathrm{h}^{\prime \prime}\right)+1$ & \\
Wan and Fell & $\mathrm{P}=\exp (\mathrm{Z}) /[1-\exp (\mathrm{Z})]$ & $\mathrm{P}>95 \%$ \\
$(2008)$ & $\mathrm{Z}=2.378 \log \left(\mathrm{h}^{\prime \prime}\right)-$ & \\
& $3.648 \mathrm{~h}^{\prime}+3.701$ & \\
\hline
\end{tabular}

$\mathrm{U}=$ unstable; $\mathrm{P}=$ probability of internal instability. 


\subsection{Sample formation procedure}

In this section, two sample formation methods will be described. The first involves forming a sample with uniform density and homogenous particle size distribution. The second involves preparing samples that have a homogenous particle size distribution after internal erosion.

\subsubsection{Method I: Formation of samples with uniform density and homogenous particle size distribution prior to erosion}

Moist tamping is used to form the samples as it leads to minimal particle segregation. Several thin soil layers are tamped, layer by layer, to form a sample. The modified 'undercompaction' method of Vo and Russell [17] is employed to achieve samples with uniform density. The compaction energy applied to each layer of soil in forming the sample is controlled in order to achieve a uniform density throughout the sample. An electric Kango percussion hammer fitted with a round steel pad with a diameter of $195 \mathrm{~mm}$ is used to apply compaction energy. The relationships between compacting duration and dry density for a single layer, having a moisture content of $7.3 \%$, are obtained as shown in Fig. 3 .

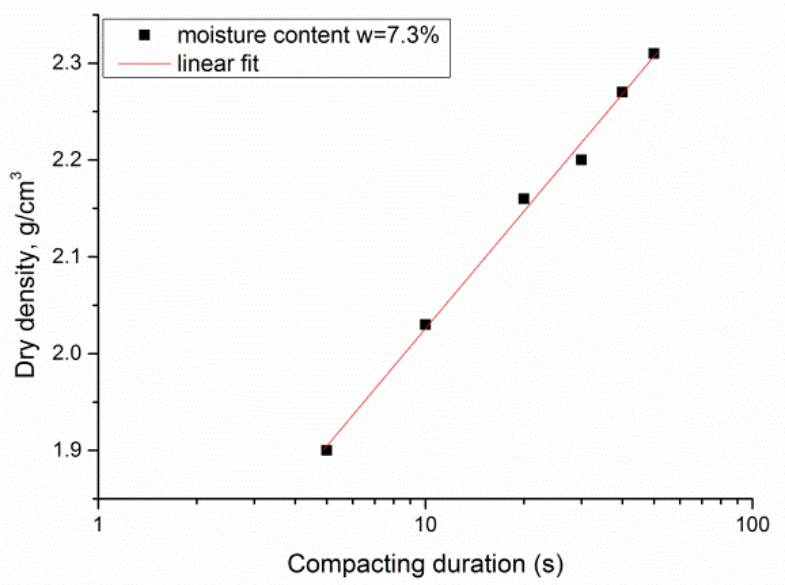

Fig. 3. Compacting durations versus dry density of soil.

According to Skempton and Brogan [18] and Fell and Wan [19], cohesionless soils compacted to a relative density greater than $65 \%$ have a low likelihood of internal erosion. In this study, all the samples are prepared targeting a density of $2.08 \mathrm{~g} / \mathrm{cm}^{3}$ when the moisture content is $7.3 \%$, which corresponds to a relative density of $50 \%$. The corresponding compacting duration for a single layer to reach the target is $14.5 \mathrm{~s}$. Compaction trials on a layered soil showed that, when the top layer was subjected to 14.5 seconds of compaction, the top layer absorbed $75 \%$ of compaction energy, the second layer absorbed $20 \%$ of the compaction energy and the third layer absorbed $5 \%$ of the compaction energy. It follows, using the Vo and Russell technique [17], that the compaction times for each layer of a six layered sample are $14.5,14.5,14.6,14.3,14.2,19.3 \mathrm{~s}$, from bottom to top, to produce a sample with a density of $2.08 \mathrm{~g} / \mathrm{cm}^{3}(50 \%$ relative density) throughout. The uniformity of the density of a sample was checked by measuring the thickness of each layer. The maximum, minimum and average ratios are $1.08,0.99$ and 1.03 , respectively.

The particle size distribution which results posterosion is determined. A sample is divided into quarters, with the 1 st quarter at the top and the 4th quarter at the bottom. The particle size distribution curve of each quarter is determined by sieving [20]. Typical posterosion particle size distribution curves are shown in Fig. 4. The curves are generally shifted downwards and have significantly reduced fines contents compared to the initial. It is also noticeable that there is greater fine particle loss in the 1st quarter. Also, the middle two quarters of the sample are relatively uniform after internal erosion. These are in general agreement with observations made by $[2,4$, 7].

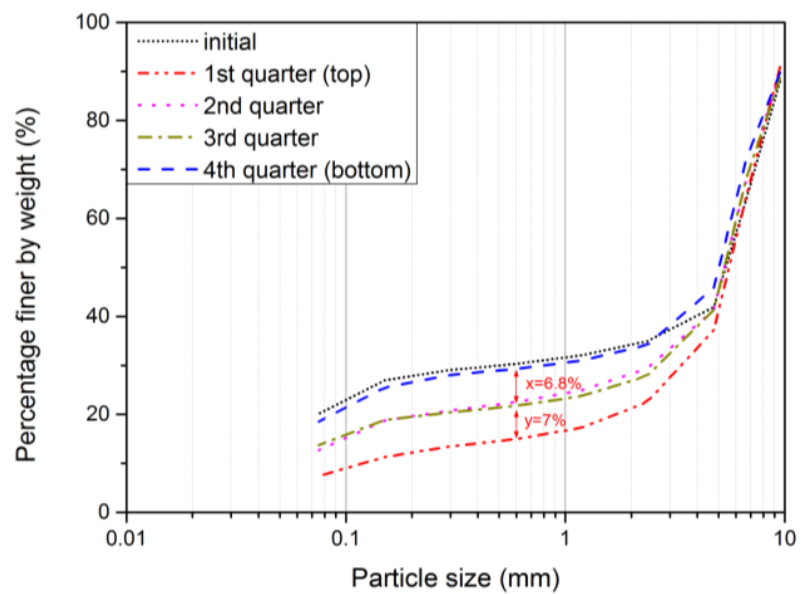

Fig. 4. Typical post-erosion grading curves.

\subsubsection{Method II: Formation of samples with uniform post-erosion grading curves}

In this procedure fine particles are relocated in each of the six layers during the formation of the sample to achieve a more uniform post-erosion particle size distribution. From the typical post-erosion particle size distribution results shown in Figure 4, for a sample with uniform density and particle size distribution prior to erosion, after erosion there ended up being about $7 \%$ more fines in the top quarter than that in the middle two quarters. There were also $7 \%$ fewer fines in the $4^{\text {th }}$ quarter. Thus, in order to achieve a homogenous particle size distribution after erosion, 7\% more fines (silica and $5 \mathrm{~mm}$ basalt) were added in the upper two layers during compaction, and 7\% fewer fines were contained in the bottom two layers, with the middle two layers having a particle size distribution the same as the target. The compacting duration for the bottom, middle and top layers thus has to be adjusted to obtain a uniform density. Samples were compacted at a moisture content of $7.3 \%$. After compaction, the uniformity of the density of a sample was checked. The maximum, minimum and average ratios between actual density and target density are 1.07, 0.97 and 1.04, respectively. 


\section{Test procedure, results and discussion}

After preparation a sample is placed in the triaxial cell and then saturated by using elevated back pressure. It is then consolidated under an isotropic confining stress of $50 \mathrm{kPa}$. An erosion test is then performed under a hydraulic gradient of $i=3.1$.

Two samples formed by two methods described in section 3.2 are subjected to same amount of erosion by passing through 48 litres of water. The time required for the collected effluent to reach certain volumes is recorded. The seepage direction is reversed after every 8 liters of seepage, causing the effective stress gradients to be reversed also. The changes in volume of the samples during erosion are determined using the cell volume changes, and the axial settlements are measured using the laser pointer.

After erosion and the subsequent triaxial test each sample is quartered and the particle size distribution of each is determined by wet sieving. Those for a sample formed using method II, after being subjected to 48 litres of seepage, are shown in Fig. 5. All grading curves are moved downward from the equivalent initial position by almost same distance. Compared to the post-erosion particle size distribution of samples formed by method I, showing in Fig. 4, the homogeneity of the eroded sample has been improved significantly.

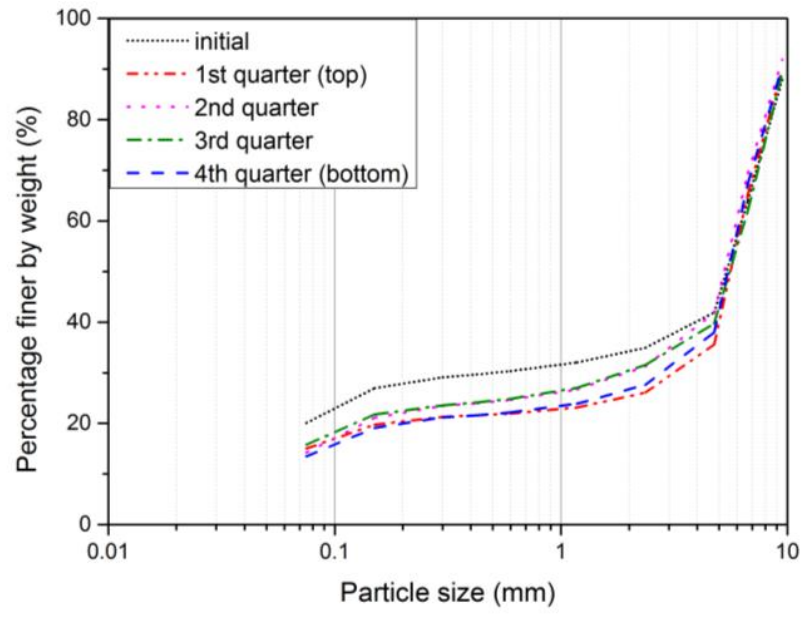

Fig. 5. Post-erosion particle size distribution for sample formed by sample formation method II.

\section{Conclusion}

Internal erosion tests on samples formed by a conventional sampling procedure result in nonhomogeneous post-erosion particle size distributions. A new sample formation method is proposed in this paper, in which the particle size distributions of the pre-erosion sample are adjusted so that a homogenous distribution results post-erosion. It is capable of obtaining a more homogeneous post-erosion particle size distribution compared to what results from a conventional sample formation procedure.

\section{References}

1. M. Foster, R. Fell, M. Spannagle, Can. Geotech. J., 37, 1000-1024 (2000)

2. D. Chang, L. Zhang, Geotech. Test. J., 34, 579589 (2011)

3. D. Chang, L. Zhang, J. Cheuk, HKIE Trans., 21, 198-208 (2014)

4. L. Ke, A. Takahashi, Geotech. Test. J., 37, 347364 (2014)

5. L. Ke, A. Takahashi, Soils and Found., 52, 698711 (2012)

6. M. Xiao, N. Shwiyhat, Geotech. Test. J., 35, 890-900 (2012)

7. T. Kenney, D. Lau, Can. Geotech. J., 22, $215-$ 225 (1985)

8. M. Sato, R. Kuwano, Soils and Found., 55, 829840 (2015)

9. C. F. Wan, "Experimental investigations of piping erosion and suffusion of soils in embankment dams and their foundations," University of New South Wales (2009)

10. F. Bendahmane, D. Marot, A. Alexis, J. Geotech. Geoenv. Eng., 134, 57-67 (2008)

11. W. Sherman, "Filter Experiments and Design Criteria," Army engineer waterways experiment station vicksburg miss (1953)

12. V. Istomina, Gostroizdat, Moscow, Leningrad, 15, (1957)

13. E. Lubochkov, Izvestia, vniig, 78, 255-280 (1965)

14. A. Kézdi, "Soil physics-selected topicsdevelopments in geotechnical engineering-25" (1979)

15. V. Burenkova, Filters in geotechnical and hydraulic engineering. Balkema, Rotterdam, 357-360 (1993)

16. C. F. Wan, R. Fell, J. Geotech. Geoenv. Eng., 134, 401-407 (2008)

17. T. Vo, A. R. Russell, Int. J. Phys. Mod. Geotech., 13, 63-78 (2013)

18. A. Skempton, J. Brogan, Geotechnique, 44, 449460 (1994)

19. R. Fell, C. F. Wan, J. Cyganiewicz, M. Foster, J. Geotech. Geoenv. Eng., 129, 307-314 (2003)

20. A. Standard, D6913-04, Standard Test Methods for Particle-Size Distribution (Gradation) of Soils Using Sieve Analysis. American Society for Testing and Materials, West Conshohocken, PA. Retrieved from ASTM Digital Library (2009) 